OPEN ACCESS

Approved by:

Frontiers Editorial Office,

Frontiers Media SA, Switzerland

*Correspondence:

Diana Abondano Almeida

AbondanoAlmeida@bio.uni-frankfurt.de

tPresent address: Diana Abondano Almeida,

Department of

Wildlife-/Zoo-Animal-Biology and

Systematics, Faculty of Biological

Sciences, Goethe-Universität Frankfurt am Main, Frankfurt, Germany

Swanne Gordon,

Department of Biology, Washington University in St. Louis, St. Louis, MO,

United States

Specialty section:

This article was submitted to Behavioral and Evolutionary Ecology,

a section of the journal

Frontiers in Ecology and Evolution

Received: 07 July 2021

Accepted: 08 July 2021

Published: 29 July 2021

Citation:

Almeida DA, Mappes J and Gordon S (2021) Corrigendum:

Predator-Induced Plasticity on

Warning Signal and Larval Life-History

Traits of the Aposematic Wood Tige

Moth, Arctia plantaginis.

Front. Ecol. Evol. 9:737651.

doi: 10.3389/fevo.2021.737651

\section{Corrigendum: Predator-Induced} Plasticity on Warning Signal and Larval Life-History Traits of the Aposematic Wood Tiger Moth, Arctia plantaginis

\author{
Diana Abondano Almeida ${ }^{1,2 * t}$, Johanna Mappes ${ }^{1,3}$ and Swanne Gordon ${ }^{4 \dagger}$ \\ ${ }^{1}$ Department of Biological and Environmental Science, University of Jyväskylä, Jyväskylä, Finland, ${ }^{2}$ Department of \\ Wildlife-/Zoo-Animal-Biology and Systematics, Faculty of Biological Sciences, Goethe Universität, Frankfurt, Germany, \\ ${ }^{3}$ Organismal and Evolutionary Biology Research Programme, Faculty of Biological and Environmental Sciences, University of \\ Helsinki, Helsinki, Finland, ${ }^{4}$ Department of Biology, Washington University in St. Louis, St. Louis, MO, United States
}

Keywords: predation, Plastic response, Aposematism, Life-history, antipredator, Larva, Costs, maladaptation

\section{A Corrigendum on}

Predator-Induced Plasticity on Warning Signal and Larval Life-History Traits of the Aposematic Wood Tiger Moth, Arctia plantaginis

by Almeida, D. A., Mappes, J., and Gordon, S. (2021). Front. Ecol. Evol. 9:658177. doi: $10.3389 /$ fevo.2021.658177

In the published article, there was an error regarding the affiliation for Diana Abondano Almeida. As well as having affiliation 2, they should also have Department of Wildlife-/Zoo-Animal-Biology and Systematics, Faculty of Biological Sciences, Goethe Universität, Frankfurt, Germany.

The authors apologize for this error and state that this does not change the scientific conclusions of the article in any way. The original article has been updated.

Publisher's Note: All claims expressed in this article are solely those of the authors and do not necessarily represent those of their affiliated organizations, or those of the publisher, the editors and the reviewers. Any product that may be evaluated in this article, or claim that may be made by its manufacturer, is not guaranteed or endorsed by the publisher.

Copyright (c) 2021 Almeida, Mappes and Gordon. This is an open-access article distributed under the terms of the Creative Commons Attribution License (CC BY). The use, distribution or reproduction in other forums is permitted, provided the original author(s) and the copyright owner(s) are credited and that the original publication in this journal is cited, in accordance with accepted academic practice. No use, distribution or reproduction is permitted which does not comply with these terms. 